Tropical Journal of Pharmaceutical Research November 2021; 20 (11): 2241-2248

ISSN: $1596-5996$ (print); 1596-9827 (electronic) (C) Pharmacotherapy Group, Faculty of Pharmacy, University of Benin, Benin City, 300001 Nigeria

\title{
Characterization of bilayered matrix-type mucoadhesive buccal films containing tizanidine hydrochloride and piroxicam
}

\author{
M. Yasmin Begum ${ }^{1 *}$, Ali Alqahtani² \\ ${ }^{1}$ Department of Pharmaceutics, ${ }^{2}$ Department of Pharmacology, College of Pharmacy, King Khalid University, Abha, Kingdom of \\ Saudi Arabia \\ *For correspondence: Email: yaminimp47@gmail.com; Tel: +966-537860241, +91-9989822643
}

Sent for review: 9 February 2021

Revised accepted: 20 October 2021

\begin{abstract}
Purpose: To formulate and characterize tizanidine hydrochloride (TZN) and piroxicam (PRX)-loaded bilayer mucoadhesive buccal films with an intention to improve the bioavailability and patient compliance in pain management.

Methods: Bilayer buccal films were prepared by solvent evaporation technique using hydroxypropyl methylcellulose (HPMC) 15cps and polyvinylpyrrolidone (PVP K30 as immediate release (IR) layer forming polymers and HPMC K15 M, PVP K 90 along with various muco adhesive polymers (Carbopol $P 934$, sodium alginate, etc), as sustained release (SR) layer forming polymers. The prepared films were characterized for thickness, weight variation, folding endurance, surface $\mathrm{pH}$, swelling index, mucoadhesive strength, in vitro residence time, in vitro drug release, ex vivo permeation and drug release kinetics.

Results: The prepared films were of largely uniform thickness, weight and drug content. Moisture loss (\%) and folding endurance were satisfactory. Surface $\mathrm{pH}$ was compatible with salivary fluid. Disintegration time was $85 \mathrm{~s}$ for $\mathrm{F} 1$ and $115 \mathrm{~s}$ for F2 of IR films. In vitro dissolution studies showed $99.12 \pm 1.2 \%$ (F1) and $90.36 \pm 1.8 \%$ (F2) were released in $45 \mathrm{~min}$. Based on the above results, F1 was chosen as the optimum formulation to be combined with SR layer of TZN. Amongst the SR layers of TZN in vitro drug release. The findings show that of F2 was $98.38 \pm 0.82 \%$ and correlated with ex vivo release. Drug release followed zero order release kinetics and mechanism of drug release was non-Fickian type diffusion. In vitro residence time was greater than $5 \mathrm{~h}$.

Conclusion: The findings show that the bilayer buccal films demonstrate the dual impact of delivering PRX instantly from the IR layer, with good controlled release and permeation of TZN from the SR layer, thus providing enhanced therapeutic efficacy, drug bioavailability and patient compliance.
\end{abstract}

Keywords: Piroxicam, Tizanidine, Carbopol P934, Sodium alginate, Polyvinylpyrrolidone, Chitosan, Hydroxylpropyl methyl cellulose

This is an Open Access article that uses a funding model which does not charge readers or their institutions for access and distributed under the terms of the Creative Commons Attribution License (http://creativecommons.org/licenses/by/4.0) and the Budapest Open Access Initiative (http://www.budapestopenaccessinitiative.org/read), which permit unrestricted use, distribution, and reproduction in any medium, provided the original work is properly credited.

Tropical Journal of Pharmaceutical Research is indexed by Science Citation Index (SciSearch), Scopus, International Pharmaceutical Abstract, Chemical Abstracts, Embase, Index Copernicus, EBSCO, African Index Medicus, JournalSeek, Journal Citation Reports/Science Edition, Directory of Open Access Journals (DOAJ), African Journal Online, Bioline International, Open-J-Gate and Pharmacy Abstracts

\section{INTRODUCTION}

Systemic target of drugs via oral cavity's buccal mucosal membrane is termed as buccal drug delivery system. Inner region of cheeks in oral cavity is lined with buccal mucosal membrane. In buccal drug delivery, the product is kept between upper gingiva \& cheek for treating local \& 
systemic disorders [1]. Buccal route of drug delivery is a striking target, particularly in choking deficiencies connected with the conventional genre of administration [2]. Rapid onset of action and discontinuation of therapy if side effects persist can be the superlative benefits relative to the oral route. Buccal drug delivery is also suited to manage patients who are unconscious and non-co-operative [3]. Facilitation of close contact and interaction of the dosage form with absorption surface in buccal muco-adhesive drug delivery system contributes to prolonged, improved and better therapeutic concert of the drug [4].

A retrospective study conducted by Smith et al in 2001 states that tizanidine hydrochloride (TZN) at low dose in combination with a regular longacting NSAID might be useful in treating analgesic rebound headache. This treatment is a wonderful bridge during the period of analgesic withdrawal. When a series of patients tested by smith et al, it was found that the treatment was well accepted and unveiled a high degree of efficacy [5].

Thus, bilayered mucoadhesive buccal film containing piroxicam (PRX) loaded immediate release (IR) layer and TZN loaded sustained release (SR) layer was prepared to have better patient compliance and enhanced bioavailability.

A $\alpha_{2}$ receptor agonist, TZN, which comes under the category of imidazoline derivative produces myotonolytic effects on skeletal muscle much analogous to clonidine and other $\alpha_{2}$-adrenergic agonists. Orally administered TZN is reported to have 53 to $66 \%$ of the absorption and attain $\mathrm{C}_{\max }$ within 2.5 to $4 \mathrm{~h}$ [4]. TZN has bioavailability of about 21 to $40 \%$ and $2-2.5 \mathrm{~h}$ of half-life with $30 \%$ of plasma protein binding [4]. Furthermore, it was reported that approximately $95 \%$ of a dose of orally given TZN metabolised in the liver during its first pass is the prime reason for reduced bioavailability of TZN. Thus, to improve the bioavailability of TZN by circumventing the large hepatic first-pass elimination, the drug was chosen as a suitable one for incorporating into muco adhesive buccal film.

Piroxicam (PRX), a NSAID, is highly efficacious in the management of numerous pain disorders. As per biopharmaceutical classification system (BCS) PRX is classified as class II drug having poor solubility in water with good permeability characteristics. Poor water solubility might be a reason for its poor bioavailability and hence effectiveness [6].
Thus, the present study design was with the goal of evolving a dosage form, proficient to deliver TZN and PRX together to improve patient adherence and to alleviate pain.

\section{EXPERIMENTAL}

\section{Materials}

Tizanidine Hydrochloride (TZN) was obtained from Aizant Drug Research Solutions Pvt Ltd, Hyderabad, India. Piroxicam (PRX) was procured from Aurobindho Pharma Pvt Ltd, India. Carbopol P 934, hydroxypropyl methylcellulose (HPMC) K15M, HPMC (K4M), HPMC (15 cps viscosity grade), chitosan, polyvinyl pyrrolidone (PVP) K30, polyvinyl pyrrolidone (PVP) K90 and sodium alginate were obtained from Sigma Aldrich. All the other chemicals and solvents are generally regarded as safe (GRAS).

\section{Preparation of PRX-laded immediate release (IR) layer}

Films were prepared by solvent evaporation technique. The calculated quantity of drug $(10 \mathrm{mg}$ per $\mathrm{cm}^{2}$ ) was dissolved in $1 \mathrm{ml}$ of ethanol. The required amount of PVP K30 and HPMC $15 \mathrm{cps}$ were dissolved in water as per the formula (Table 1). The drug solution was added to the polymer solution. The whole mix was vortexed at $400 \mathrm{rpm}$ using magnetic stirrer. The drug polymer mixture was poured into a petri plate and dried at room temperature. The patch was separated from petri plate and stored in a desiccator [4].

Table 1: Composition of PRX-loaded IR layer of muco adhesive buccal film

\begin{tabular}{lccc}
\hline Content & \multicolumn{3}{c}{ Formulation code } \\
\cline { 2 - 4 } & F1 & F2 & F3 \\
\hline Piroxicam (mg) & 10 & 10 & 10 \\
HPMC, 15 cps (\%w/w) & 1 & 1.5 & 2 \\
PVP K30 (\%w/w) & 1 & 0.5 & -- \\
Propylene glycol (\%v/v) & 5 & 5 & 5 \\
Water (mL) & 15 & 15 & 15 \\
\hline
\end{tabular}

\section{Preparation of TZN-loaded sustained release (SR) layer}

Mucoadhesive buccal films were made by solvent evaporation method. The calculated quantity of drug (2 $\mathrm{mg}$ per $\mathrm{cm}^{2}$ of the film) was dissolved in $1 \mathrm{ml}$ of ethanol. The required amount of PVP K90 and $4 \mathrm{ml}$ of water was added to the above solution (carrier solution). The remaining polymers were added as per the composition given in Table 2 to the carrier 
solution. Five percent (5\%) propylene glycol was further added to the above solution and the entire mixture was vortexed for $1 \mathrm{~h}$ at $400 \mathrm{rpm}$ using magnetic stirrer. The drug/polymer mixture was poured into petri plate, dried at room temperature, stored in desiccator after drying [7].

Table 2: Composition of TZN-mucoadhesive buccal film

\begin{tabular}{lcccc}
\hline Content & \multicolumn{4}{c}{ Formulation code } \\
\cline { 2 - 5 } & F1 & F2 & F3 & F4 \\
\hline Tizanidine hydrochloride $(\mathrm{mg}$ & 2 & 2 & 2 & 2 \\
PVP K90 (\%w/w) & 7 & 7 & 7 & 7 \\
Sodium alginate $(\% \mathrm{w} / \mathrm{w})$ & 1.5 & 1.5 & 1.5 & 1.5 \\
HPMC K15M (\%w/w) & 1 & - & - & - \\
Carbopol P 934 (\%w/w) & - & 1 & - & - \\
HPMC K4 M (\%w/w) & - & - & 1 & - \\
Chitosan (\%w/w) & - & - & - & 1 \\
Propylene glycol (\%v/v) & 5 & 5 & 5 & 5 \\
Water (mL) & 15 & 15 & 15 & 15 \\
\hline
\end{tabular}

\section{Determination of thickness uniformity}

Micrometer was used for measuring the thickness of the films at three diverse spots of film and reported the mean with standard deviation [7].

\section{Evaluation of uniformity of weight of films}

Each film's weight was measured in a balance and the weight variation of films were calculated $(n=6)[8]$.

\section{Assessment of moisture loss}

Anhydrous calcium chloride loaded desiccator was used to measure the percentage moisture loss by locking the films $\left(1 \times 1 \mathrm{~cm}^{2}\right)$ in it for 3 days and by rechecking the weight of the films thereafter. Moisture loss \% was estimated from the difference in weight of the films.

\section{Determination of folding endurance}

The folding endurance of the films was found out by constantly folding the film to $180^{\circ}$ angle at the same place till it breaks or up to 300 times, which is considered satisfactory to disclose toughness and flexibility of the films. The maximum number of times, the films can possibly be folded at the same place without breaking provides the measure of the folding endurance [9].

\section{Measurement of surface pH}

Agar in phosphate buffer solution $\mathrm{pH} 6.8$ with the concentration of $2 \% \mathrm{w} / \mathrm{v}$ was the supporting gel media plate to measure surface $\mathrm{pH}$ of buccal films. Measurement was done by admitting the films to swell and expand for $1 \mathrm{~h}$ on the plate's surface and by bringing the electrode of $\mathrm{pH}$ meter to be in touch with the film's surface [7].

\section{Determination of drug content uniformity of films}

A film size of $1 \times 1 \mathrm{~cm}^{2}$ was cut and put in $10 \mathrm{~mL}$ of phosphate buffer solution ( $\mathrm{pH} \mathrm{6.8).} \mathrm{The} \mathrm{film}$ was completely dissolved by constant stirring and drug content was measured in phosphate buffer solution $\mathrm{pH} 6.8$ by UV-spectrophotometer at $320 \mathrm{~nm}$ for TZN and $354 \mathrm{~nm}$ for PRX [4, 8, 10] against blank.

\section{In vitro drug dissolution study of IR layer containing PRX}

The dissolution profile of IR layer of piroxicam was performed in $30 \mathrm{~mL}$ dissolution medium of the simulated salivary fluid having $\mathrm{pH} 6.8$ at $37 \pm$ $0.5^{\circ} \mathrm{C}$. The medium was mixed continuously by stirring at $100 \mathrm{rpm}$. At 5, 10, 15, 30 and $45 \mathrm{~min}$ time intervals, aliquots $(2 \mathrm{~mL})$ of the dissolution medium were taken out and replaced with an equivalent amount of fresh medium [10]. Samples were assessed spectrophotometerically at $354 \mathrm{~nm}$.

\section{Assessment of in vitro residence time of bi- layered films}

The in vitro residence time for buccal film was measured by a modified disintegration apparatus, USP. The medium was $500 \mathrm{~mL}$ of phosphate buffer $\mathrm{pH} 6.8$ at $37 \pm 0.5^{\circ} \mathrm{C}$. A part of goat buccal mucosa $3 \mathrm{~cm}$ length was glued to glass slab. After hydrating the film surface using phosphate buffer $\mathrm{pH} 6.8$ it was set into contact with the mucosal membrane. The glass slab was secured vertically on rack assembly of disintegration apparatus in such a way that there was complete immersion of the film into the buffer solution when rack assembly moves downward and it was seen out of the buffer solution when rack assembly moves upward. The time, the film took for the complete detachment from the mucosal surface was noted $(n=6)$ [11].

\section{In vitro diffusion study of bi-layered film}

In vitro drug release was studied in a modified diffusion cell using sigma membrane (12000 Molecular weight cut off) between the donor and receptor compartment of the diffusion cell. It has a $250 \mathrm{~mL}$ beaker as receptor compartment and an open-ended glass tube with the diameter $17.5 \mathrm{~mm}$ as the donor compartment. Sigma membrane (Sigma 12000 MW cutoff) was attached at one end of the tube \& the other end 
was left untouched. After securing buccal film in sigma membrane the assembly was immersed in $150 \mathrm{~mL}$ of phosphate buffer $\mathrm{pH} 6.8$ present in beaker. The whole assembly was fixed on a hot plate magnetic stirrer and stirred at $100 \mathrm{rpm}$ at the temperature $37 \pm 0.5{ }^{\circ} \mathrm{C}$. $5 \mathrm{~mL}$ aliquot samples were withdrawn at regular intervals and analysed by UV spectroscopy $[1,2]$.

\section{Ex vivo permeation study of bi-layered film}

Ex vivo percentage drug permeation was studied in a modified diffusion cell as discussed in the above section using the goat buccal mucosal membrane separating the donor and the receptor compartment of the diffusion cell. The film was positioned on the buccal mucosal membrane using aluminium foil as the backing layer. Phosphate buffer $\mathrm{pH} 6.8$ was used as the receptor compartment media. The entire assembly was secured on a hot plate magnetic stirrer and stirred at $100 \mathrm{rpm}$ at $37 \pm 0.5^{\circ} \mathrm{C} .5 \mathrm{~mL}$ aliquot samples were withdrawn at regular intervals and analysed by UV spectroscopy.

\section{Statistical analysis}

Statistical analysis of the experimental outcome was done by using One-way ANOVA with 95\% confidence interval. Unpaired $t$ test was performed by GraphPad Prism (version 5, Graphpad software, USA). A P $<0.05$ was observed as the level of significance. Value of mean and standard deviations were stated out of six trials.

\section{RESULTS}

\section{Physicochemical characteristics of IR layer of PRX}

Amongst the 3 formulations of PRX loaded IR film (F1, F2 and F3) prepared, F3 did not form film consistently. Thus, physicochemical characteristics were studied for F1 and F2 only.

The thickness and weight uniformity of the films are shown in Table 3. There was no considerable $\%$ moisture loss for F1 while F2 was $20 \%$. Measurement of folding endurance was done manually by repeatedly folding the film at a point till it broke and finding the number of times without breaking the film could be folded at the same place. Thus, the end point was fixed at breaking time. The folding endurance was greater than 300 times for both $F 1$ and F2 without any break line, wear and tear. Surface $\mathrm{pH}$ of both films were well correlating with salivary fluid. Drug content was in the range of $95-105 \%$. In vitro disintegration time determined with PRX IR layer using USP disintegration tester was $85 \mathrm{sec}$ for $\mathrm{F} 1$ and $115 \mathrm{sec}$ for F2. Based upon the above results $F 1$ was chosen as the optimum formulation to be combined with $\mathrm{SR}$ layer of TZN.

\section{Physicochemical characteristics of SR layer of TZN}

The films containing TZN (F1, F2, F3 and F4) were assessed for various physicochemical constraints like thickness, surface $\mathrm{pH}$, weight uniformity, content uniformity, folding endurance and swelling index.

The thickness of the four films were in the range of $0.62 \pm 0.02$ to $0.87 \pm 0.03 \mathrm{~mm}$. Weight of the films were from $0.043 \pm 0.0014$ to $0.083 \pm 0.0070$ g. Moisture loss (\%) was less for both F1 and F2.

The folding endurance was the highest for formulation F2 (256) and the lowest for formulation F4 (198). Surface $\mathrm{pH}$ was 6.852 correlating with salivary fluid for F2. Swelling index was the highest for F2 i.e., $27.27 \%$ (Table 4, Figure 1).

It was assumed that the polymer's high hydrophilic nature in F2 resulted in extreme swelling when compared to other films. Drug content (\%) was even for all the films ranging from $96.27 \pm 0.320(F 3)$ to $99.57 \pm 0.173(F 2)$ (Table 4).

In vitro residence time results showed that formulation F2 having carbopol P934 as the muco adhesive polymer showed higher mucoadhesion strength and hence greater in vitro residence time of more than $5 \mathrm{~h}$. From the above results, F2 was chosen as SR layer to be combined with the selected IR layer of PRX.

\section{Evaluation of bilayer buccal film}

Few tests were carried out for bilayer buccal film that contains an IR layer of PRX (F1; Table 1)

Table 3: Physicochemical characteristics of IR layer of PRX

\begin{tabular}{lcccccc}
\hline $\begin{array}{l}\text { Formulati } \\
\text { on code }\end{array}$ & $\begin{array}{c}\text { Thickness } \\
\text { in } \mathbf{~ m m}\end{array}$ & $\begin{array}{c}\text { Surface } \\
\text { pH }\end{array}$ & $\begin{array}{c}\text { Weight } \\
\text { uniformity (g) }\end{array}$ & $\begin{array}{c}\text { Content } \\
\text { uniformity } \\
(\%)\end{array}$ & $\begin{array}{c}\text { Folding } \\
\text { endurance }\end{array}$ & $\begin{array}{c}\text { Moisture } \\
\text { loss (\%) }\end{array}$ \\
\hline F1 & $0.75 \pm 0.01$ & 6.701 & $0.014 \pm 0.006$ & $99.57 \pm 0.173$ & $>300$ & 0 \\
F2 & $0.79 \pm 0.01$ & 6.893 & $0.01 \pm 0.006$ & $97.52 \pm 0.357$ & $>300$ & 20 \\
\hline
\end{tabular}


Table 4: Physicochemical characteristics of mucoadhesive buccal films of TZN

\begin{tabular}{|c|c|c|c|c|c|c|c|c|}
\hline $\begin{array}{l}\text { Formulation } \\
\text { code }\end{array}$ & $\begin{array}{l}\text { Thicknes } \\
\text { s (mm) }\end{array}$ & $\begin{array}{c}\text { Surface } \\
\text { pH }\end{array}$ & $\begin{array}{l}\text { Weight } \\
\text { (g) }\end{array}$ & $\begin{array}{c}\text { Content } \\
(\%)\end{array}$ & $\begin{array}{c}\text { Folding } \\
\text { Endurance }\end{array}$ & $\begin{array}{c}\text { Swelling } \\
\text { index } \\
(\%)\end{array}$ & $\begin{array}{c}\text { In-vitro } \\
\text { residence } \\
\text { time (h) }\end{array}$ & $\begin{array}{l}\text { Moisture } \\
\text { loss (\%) }\end{array}$ \\
\hline F1 & $0.62 \pm .02$ & 7.231 & $\begin{array}{l}0.057 \pm \\
0.0026\end{array}$ & $\begin{array}{c}97.52 \pm \\
0.357\end{array}$ & 245 & 14.51 & 3 & 1.886 \\
\hline $\mathrm{F} 2$ & $0.8 \pm 0.04$ & 6.852 & $\begin{array}{l}0.043 \pm \\
0.0014\end{array}$ & $\begin{array}{c}99.57 \pm \\
0.173\end{array}$ & 256 & 27.27 & $>5$ & 1.886 \\
\hline F3 & $0.79 \pm 0.03$ & 7.478 & $\begin{array}{c}0.068 \\
\pm 0.0063\end{array}$ & $\begin{array}{c}96.27 \pm \\
0.320\end{array}$ & 248 & 16 & 3 & 4.761 \\
\hline F4 & $0.87 \pm 0.03$ & 5.143 & $\begin{array}{l}0.083 \pm \\
0.0070\end{array}$ & $\begin{array}{c}97.59 \pm \\
0.254\end{array}$ & 198 & 22.73 & 4 & 2.352 \\
\hline
\end{tabular}

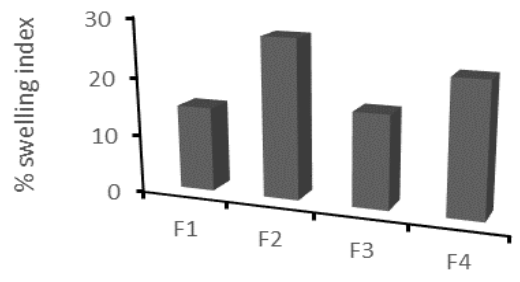

Formulation Code

Figure 1: Swelling index of films F1 to F4

and SR layer of TZN (F2; table 2). In vitro residence time test for the bilayered buccal film showed that formulation was adhering to buccal membrane for greater than $5 \mathrm{~h}$. In vitro dissolution studies was conducted for optimized IR layer of PRX and the results showed that $99.68 \pm 0.72 \%$ of PRX was released in 15 min (Figure 2).

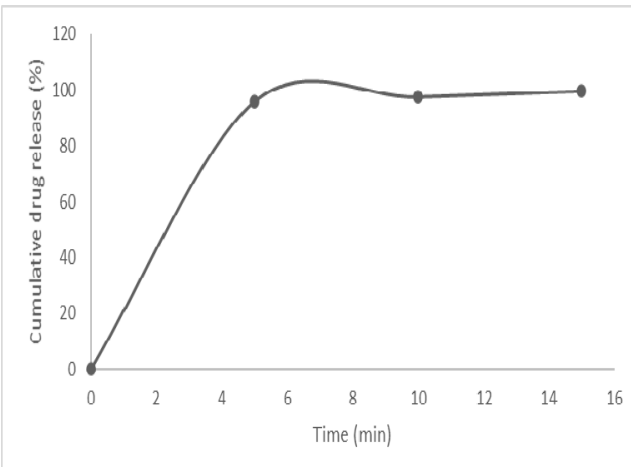

Figure 2: In vitro cumulative drug release from IR layer of PRX

The other formulation (F2) showed $90.36 \pm 1.8 \%$ in $45 \mathrm{~min}$. This is also another reason that supported the selection of $\mathrm{F} 1$ to be combined with SR layer of TZN.

SR layer of bilayered film containing TZN showed $98.38 \pm 0.82 \%$ of drug release in $6 \mathrm{~h}$ as shown in Figure 3. Results of in vitro release were found to be well correlated with ex vivo release of both SR as well as IR layer (Figure 4 and Figure 5).

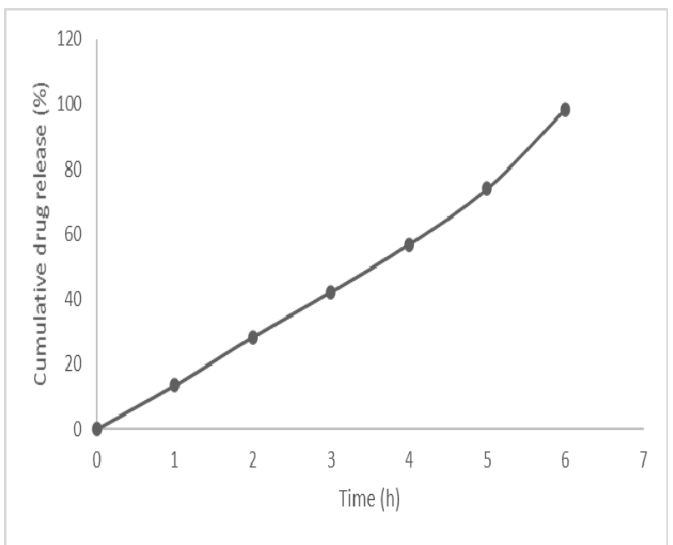

Figure 3: In vitro cumulative drug release of SR layer of TZN

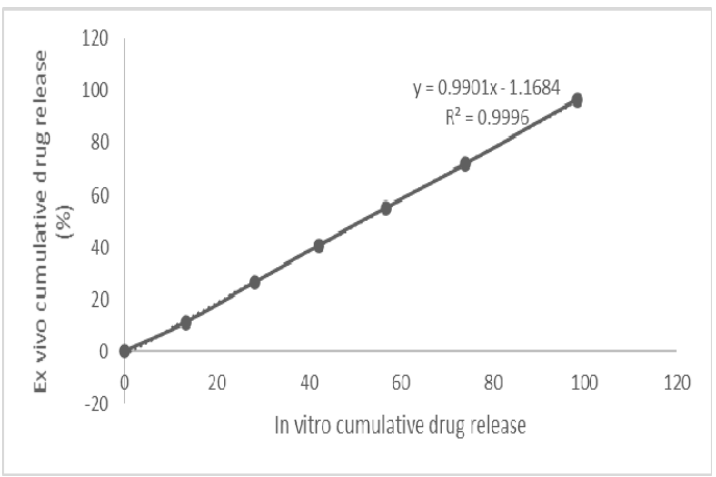

Figure 4: In vitro - ex vivo correlation of SR layer of TZN

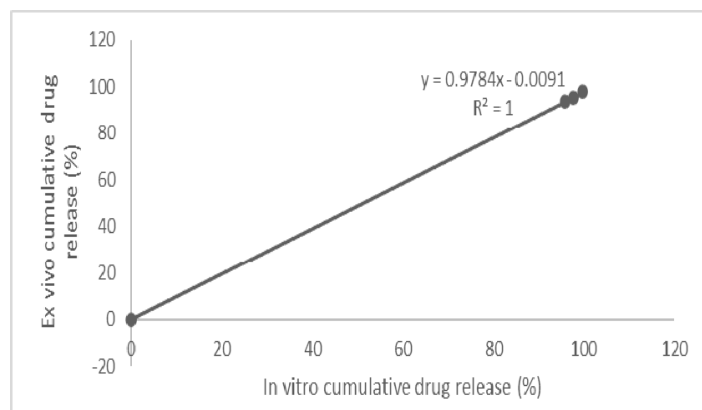

Figure 5: In vitro - ex vivo correlation of IR layer

Trop J Pharm Res, November 2021; 20(11): 2245 


\section{DISCUSSION}

Muco-adhesion is one of the most extensively used approach in delivering drugs for immediate or sustained release and to provide better bioavailability. The rich vasculature of buccal mucosa affords outstanding stage for drugs targeting into systemic circulation provided there is minimum dosage as compared to the oral route of drug delivery [11].

Both the films (F1 and F2) prepared for IR layer were flexible and elegant without any sign of cracks. Formulation F3 did not show sufficient film forming property and this might be due to the presence of extreme level of HPMC concentration. The results of thickness measurement revealed that all the films were uniform in thickness (for each formulation $<5 \%$, $\mathrm{n}=6$ ) without any significant differences at different points. From the results shown in (Table 3 ), it was found that the weight of buccal films was uniform and fluctuations in weight of the films were within the acceptable limits. The folding endurance, which is the degree of the elasticity of the films is compulsory for convenient handling of the films. All the PRXloaded IR films showed folding endurance value $>300$, indicating excellent physical and mechanical strength.

All the films had drug content $>95 \%$ with the relatively low standard deviation signifying adequate drug content in the films and the standard errors were within the limits considered to be accepted. In order to explore the possibility of any irritation effects in vivo, the surface $\mathrm{pH}$ of the buccal film was measured as it was known that extremely alkaline or acidic $\mathrm{pH}$ prone to irritate the mucosal membrane of buccal cavity.

The best film, F1, showed the surface pH 6.701. The value was very close to neutral $\mathrm{pH}$ and it is known that neutral $\mathrm{pH}$ of the film does not irritate the mucosal membrane. In vitro disintegration time was less for F1 when compared to F2. This may be due to $1: 1$ ratio of HPMC and PVP enhanced the hydrophilic property of IR layer and hence caused faster extent of disintegration when compared to F2 where the ratio of HPMC and PVP was 1.5:0.5 [12]. All the films prepared loading TZN as SR layer were also looking elegant without any surface imperfections. Table 4 summarizes the physicochemical characterization of muco-adhesive buccal films of TZN. Film thickness is a sign of dose accuracy and also a supporting factor for bioadhesion of the film [28]. The thickness of the films (F2-F4) was $\sim 0.80 \mathrm{~mm}$ (Table 4) signifying administration of film into buccal cavity does not cause any discomfort. Undoubtedly the uniform thickness of the prepared films demonstrates batch to batch drug content uniformity as well. Near neutral $\mathrm{pH}$ was observed as the surface $\mathrm{pH}$ of the prepared films ensuring no irritation or damage to the mucosa (Table 4) except F4 containing chitosan. Surface pH of F4 was 5.143. The reason might be presence of residual acetic acid that was used as the solvent for dissolving chitosan.

Analysing the content of drug in film formulations is crucial to establish the existence of drug in the films to ascertain its uniformity. The film size of 1 $x 1 \mathrm{~cm}^{2}$ was cut from different regions, and the amount of TZN was measured. All the prepared films contain more than $95 \%$ of drug content demonstrating adequate drug content and uniformity in the films with the least drug content errors and within the standard limits. It is understood from Table 4 that the film composition affects folding endurance. It is obvious that the value of folding endurance was more (256) for F2 containing carbopol P934 when compared to other formulations (F1, F3 and F4) under the current experimental conditions. The literature shows that Carbopol P934 enhances folding endurance. The crosslinking characteristics of Carbopol responsible for interpenetrating and crosslinking the polymer chains that significantly improves the mechanical properties of the system and hence folding endurance [13].

Carbopol polymeric chains also interacts extensively with small molecules of plasticizer and decreases the glass transition temperature ( $\mathrm{Tg})$ of system [14], thus increasing mechanical properties (flexibility) and subsequently improve folding endurance. Folding endurance value must be greater than 250 for a good film [15]. Film F2 showed a folding endurance value of $>$ 250 with very less standard deviation confirming the ability of F2 to withstand against damage during holding and administration of the film. Overall, the film formulations prepared displayed slight or insignificant variations in physico chemical properties such as film thickness, $\mathrm{pH}$, drug content, and folding endurance. Thus, all the physical and chemical properties were in desirable range with little variations.

Formulation F2 showed the highest degree of swelling and the reason might be optimum hydration and swelling of carbopol P934 [7]. The least \% of swelling and in-vitro residence time were found to be with film F1 and this might be due to over hydration of HPMC containing carboxylic groups, which form hydrogen bonds 
with the tissue. Formulation F2 and F4 showed disintegration time greater than $6 \mathrm{~h}$ where as $\mathrm{F} 1$ and $\mathrm{F} 3$ did not protect the integrity throughout the experimentation and were disintegrated within $3 \mathrm{~h}$. The formulation F2 showed the cumulative $\%$ drug release of $98.24 \%$ in $6 \mathrm{~h}$. This result might be due to optimum swelling of film F2 makes a thick gel barrier that slows down the drug release since diffusional path length increases [16]. The evaluation of drug release kinetics indicated that formulation F2 followed zero order controlled release. Drug release data was further fitting the best to the KorsmeyerPeppas model with $n$ value of 0.4683 and $R^{2}$ value of 0.997 and showing an excellent degree of statistical significance $(p<0.001)$. This indicated that the drug release was non-Fickian type of diffusion (Table 5) [17]. These results lead to an assumption that the drug permeation followed both paracellular and transcellular pathways [9]. The ex vivo \% drug diffusion was found to be well correlated with in vitro results.

The bilayered film containing SR layer showed the cumulative \% drug release of $98.38 \pm 0.82 \%$ in $6 \mathrm{~h}$. This result might be due to optimum swelling of film F2 [16]. IR layer of PRX showed $99.68 \pm 0.72 \%$ drug release in $15 \mathrm{~min}$. This might be due to high hydrophilicity of polymer composition [18]. The ex vivo \% drug diffusion using goat buccal mucosal membrane was found to be well correlated with in vitro results which is also an assurance for the integrity of the formulation and in vitro results obtained.

\section{CONCLUSION}

Adequately thin, mechanically tough and pliable bilayer mucoadhesive buccal films containing IR layer of PRX with a 6-h TZN release and > 5-h in vitro residence time have been developed. The combination of carbopol P 934, PVP K90 and sodium alginate in SR layer results in zero order drug release pattern. Thus, the developed bilayer buccal film can potentially enhance therapeutic efficacy, drug bioavailability and patient compliance.

\section{DECLARATIONS}

\section{Acknowledgement}

This research was funded by the Deanship of Scientific Research through General Program (no. 314-42) of King Khalid University, Abha61421, Saudi Arabia, for which the authors are grateful.

\section{Conflict of Interest}

No conflict of interest associated with this work.

\section{Contribution of Authors}

The authors declare that this work was done by the authors named in this article and all liabilities pertaining to claims relating to the content of this article will be borne by them.

\section{Open Access}

This is an Open Access article that uses a funding model which does not charge readers or their institutions for access and distributed under the terms of the Creative Commons Attribution License (http://creativecommons.org/licenses/by/ 4.0) and the Budapest Open Access Initiative (http://www.budapestopenaccessinitiative.org/rea d), which permit unrestricted use, distribution, and reproduction in any medium, provided the original work is properly credited.

\section{REFERENCES}

1. Sahar S, Soheil B. New formulation and approach for mucoadhesive buccal film of rizatriptan benzoate. Prog Biomater 2017; 6: 175-187.

2. Nayak AK. Formulate Calcium Pectinate-fenugreek seed mucilage Mucoadhesive beads for Controlled Delivery of Metformin HCl. Carbohydr Polym 2013; 96(1): 667-699.

3. Freitas-Blanco VSD, Franz-Montan M, Groppo FC, Carvalho JE, Figueira GM, Serpe L, Oliveira Sousa IM, Guilherme Damasio VA, Yamane LT, de Paula E, et al. Development and Evaluation of a Novel Mucoadhesive Film Containing Acmella oleracea Extract for Oral Mucosa Topical Anesthesia. Plos One 2016; 11(9): 118.

4. Harikrishnan $V$, Madhusudhan $S$, Santhiagu $A$. Development and in Vitro Evaluation of Tizanidine hydrochloride Buccal Tablet using Tamarind Seed Gum. J Pharm Sci Res 2016; 8(3): 161-167.

5. Smith TR. Low Dose Tizanidine Combined With LongActing NSAIDs for Detoxification From Analgesic Rebound Headache. American Headache Society 2001.

6. Mostafa K, Reza M, Shima T, Peyman K, Kazem M. A combination therapy of nanoethosomal piroxicam formulation along with iontophoresis as an anti-inflammatory transdermal delivery system for wound healing. Int Wound J 2019; 16(5): 1144-1152.

7. Xiao-Qin L, Zhao-Ming $Y$, Jian-Bing $W$, Cai-Rong $F, A i-$ Wu P, Cong L, Ren-Bing Z. Mucoadhesive buccal films of tramadol for effective pain management. Rev Bras Anestesiol 2017; 67(3): 231-237.

8. Lakshmi PK. Dhanalakshmi K, Kalyani N, Prasanthi D. preparation and evaluation of mucoadhesive bilayered

Trop J Pharm Res, November 2021; 20(11): 2247 
buccal patches of lamotrigine. Am J 2017; 7(1): 2249 3387.

9. Amr MES, Marwa HS, Ahmed HE. Formulation and optimization of duloxetine hydrochloride buccal films: in vitro and in vivo evaluation. Drug Deliv 2017: 24(1): 1762-1769.

10. Anroop BN, Abbas AA, Bandar EAl, Azza AH. Mucoadhesive Film Embedded with Acyclovir Loaded Biopolymeric Nanoparticles: In vitro Studies. J Young Pharm 2017; 9(1): 100-105.

11. Pooja K, Rajendra D, Amol, Sachin, Abhimanyu B. Studies on Rebamipide Loaded Gastroretentive Alginate Based Mucoadhesive Beads: Formulation \& In-vitro, Invivo Evaluation. Pharm Methods 2016; 7(2): 132-138.

12. Ravikumar Reddy J, Muzib I, Chowdary KPR. Development and in vivo characterization of novel trans buccal formulations of Amiloride Hydrochloride. J Pharm Res 2013; 6(6): 647-652.

13. Kazemi Z, Taghizadeh SM, Lahootifard F. Effect of composition on mechanical and physicochemical properties of mucoadhesive buccal films containing buprenorphine hydrochloride: From design of experiments to optimal formulation. J Drug Deliv Sci Technol 2020; 56: 01-18.

14. Jantrawut $P$, Chaiwarit $T$, Jantanasakulwong $K$, Brachais $C$, Chambin O. Effect of plasticizer type on tensile property and in vitro indomethacin release of thin films based on low-methoxyl pectin. Polymers 2017; 9:289.

15. Al-Dhubiab BE. Aripiprazole nanocrystal impregnated buccoadhesive films for schizophrenia. J Nanosci Nanotechnol 2017;17(4):2345-52.

16. Muaadh AMA, Ahmed MS, Bassam AA. Formulation and Evaluation of Baclofen Mucoadhesive Buccal Films. FABAD J Pharm Sci 2017; 42(3): 179-190.

17. Barzoki JM, Emam-Djomeh Z, Mortazavian E, MoosaviMovahedi AA, Tehrani MR. Formulation, in vitro evaluation and kinetic analysis of chitosan-gelatin bilayer muco-adhesive buccal patches of insulin nanoparticles. J Microencapsul 2016; 33(7): 613-624.

18. Pries M, Woertz C, Schneider K, Kukawka J. Design and evaluation of bilayered buccal film preparations for local administration of lidocaine hydrochloride. Euro J Pharm Biopharm 2014; 86: 552-561. 